\title{
Time and Body in New Media Art
}

\author{
Shu Zhong, * \\ ${ }^{1}$ Sichuan University, Chengdu, Sichuan, China \\ ${ }^{*}$ Corresponding author. Email: 64364814@qq.com

\begin{abstract}
This article focuses on the issue of time in new media art. Taking video art as an example, it provides various technical means to break the linear structure of time, thereby generating an internal view of time. This view of time is closely related to the presence of the body. The similarity between new media art and traditional art is that it continues the media's pursuit and love of the body theme, and still plays the role of body redemption narrative. But in contrast, new media art is a kind of "time-based art". Time strengthens the philosophical inquiry and artistic expression of the body. Therefore, time and body are topics that new media art needs to pay more attention to outside the media.
\end{abstract}

Keywords: body, time, video art, time-based media art

\section{INTRODUCTION}

The concept of time varies from culture to culture, and its concept is influenced by art history; it is hidden in the Hindu, Buddhist philosophy of reincarnation of time and the linear time concept conveyed by Christianity, as well as in the synchronic and diachronic concepts of modern digital technology. When we say that a work of art has time, it means that it presents a symbolic process and completes a subject reference beyond itself. The time theme in visual art works is usually related to recording and narrating events. Time is like a monument, which metaphors events or praises by means of concrete or abstract sculpture. Time in the hands of artists is a state that can be pinched, deconstructed or reorganized. Time assisted art provides a variety of narrative possibilities and expressions, which are often used in film or video art.

\section{CONTINUATION OF TIME THEME IN NEW MEDIA ART}

The static media such as painting or sculpture have some limitations in expressing the passage of time, but they also provide some special display ways. For example, in ancient Egyptian relief murals and traditional Chinese painting manuscripts, there is a similar use of multi-screen, emphasizing the presence of two or more scenes in the same story at the same time. The multi act forms of Christian art are presented from the double side painting, the triple fold painting to the multiple independent panels displayed under the religious altar decoration painting. The display of triptych, which is still used in painting, sculpture or new media image installation art today, is often regarded as the indication of religious or nostalgic narrative. Video artist bill viola is good at using triptych or multi-screen video devices and has obvious religious metaphorical features on display.

As an important theme of contemporary art, time involves all kinds of media, methods and concepts. Time is often paradoxical, linear, synchronous, or nonlinear, which seems predictable but unpredictable. No matter what form time is embodied in, the pace of time moving in its structure is always subtle and dramatic. The usual structural elements of time include length, speed, rhythm and direction. An important means for artists to manipulate time is to break the order of time. Media artists are good at capturing and recording time fragments in a state of conflict or confusion. Behind the fragmented time refers to a set of narrative words, that is, time, events and subjects are all presented in the form of fragmentation, the linear structure of time is disintegrated, numerous micro narratives replace the grand narratives under logos centralism, and the meaning flashes and disappears in an instant.

The new media artists create the dislocation of time by breaking the internal logical relationship to experiment and create. The creation of video art has inherent advantages in changing the time structure. It can realize non-linear editing by flashback, jumping clip, fading in and out, speeding up or slowing down the lens. On this basis, video art is called "time-based art". This is a kind of art form that combines the interpretation of time and space to enhance the perception of the audience to a four-dimensional space. To some extent, it can be seen as the blessing of body presence on the expression of time. New media art includes the part of time expression into the composition of the work, and emphasizes the perception of the body (from the subject or object). Time and body conspire to explain the connotation of 
"time-based art". The multidimensional space created by time and body is convenient for the audience to feel the passage, reorganization and Deconstruction of time.

\section{TIME IN THE HISTORY OF MEDIA ART: BODY AS A METAPHOR OF TIME}

Artist Nam June Paik published an article on "input time" and "out time" in the "video art" anthology, aiming at the situation that artists tamper with or re edit behavioral performance art and occasional art through video editing. He emphasized the editing techniques in video art, just like the relationship between human consciousness and memory, which are stored in the brain at the same time, but can be processed arbitrarily. He believes that "the free compilation processing in artistic creation is a simulation of the brain's processing information function," and Nam June Paik believes that video art has opened a unique artistic grammar and generated an internal flexible mode, that is, the time structure can be real or deliberately fabricated. Like the human brain, video art has absolute control over the stored content, "in a sense, as long as a person records the video, he will achieve immortality." He used this theory to create a video in memory of John Milton cage Jr. he used the rewind form of cage Jr's life video with pocket watch and other elements to complete the reproduction of a silent concert.

Hans belting, a German art historian, also agrees that video art has its own time form, similar to the time grammar in movies. In the process of screening, it presents a sense of "performing" time. Not only that, if the video itself is not properly kept, it will become a kind of perishable material and become a victim of time. Belting believes that the time of media art is not the same as the time in media art. Taking video art as an example, video media is an "electronic mirror". Inside and outside the mirror, there is a view of "internal time" caused by media. Video art, for example, as a new medium, on the one hand, can dispose of time arbitrarily in terms of technical techniques; on the other hand, the time after being technically reset is full of the subjective intention of the creator, so it is understood as the artist's own internal view of time. This subjective fabrication and technological creation of time is the artist's experience reconstruction in the media, which belongs to the artist's personal view of time. Nam June Paik, a new media artist mentioned above, has repeatedly emphasized that media reshapes the experience of human (body) presence. Artists take advantage of the internal time concept to provide a new concept or ideology, and put time, people, body and media into the same dimension for re consideration. Here, the body becomes the evidence of re understanding the representation of time.
How does video art relate to the body? In the 1960s, the beginning of video art was closely related to the action art and media performance induced by the ideas of concept art, Dadaism and wave school. At that time, on the one hand, the body, as a symbol of pioneer and revolution, was often adopted by radical artists for the expression of political position and avant-garde art. On the other hand, the body is also regarded as the object of expression, which is included in the micro narrative of daily life. David Antin, a theorist, believes that the most significant difference between artists' videos and television is their relationship to time. The former (because of the close relationship between content and reality) can be described as "boring or lengthy" even if it is very short. The latter can easily control the time through entertainment consumption and providing the public with life information (advertising and other behaviors). The possession of time by video art has the nature of criticizing mass culture. The popularity of video art has brought about "an artistic grammar, similar to literary style, which will stop only when its weak narrative energy is exhausted." Therefore, in the video art, time can be an explicit expression as well as an invisible narrative depends on the artist's selfexamination and self-consciousness of "internal time".

The artist who is keen to express "the view of inner time" is Bill viola. In his image works, the body is a living medium. For example, in 1992 "Nantes triptych" was composed of images of three screens. Synchronicity presented the process of life from birth to decay. Time is fixed in two images of the baby and the old woman to complete the self-body reference under the theme of life and death. The video installation work created by South African female artist Candice breitz "he and her: 1968-2008" ("Fig. 1"), in which the actress is Meryl street and the actor is Jack Nicholson. The device is respectively played in two connected rooms, and each part is composed of seven small screens. The artist tries to test "human nature" with the lens. In the simple background, the actors are cut out from different movie segments, and the changes of people's spiritual outlook and living conditions in the past 40 years are interpreted by different personality traits. The two actors form a kind of tension on the play, which realizes the synchronic presence in the diachronic space.

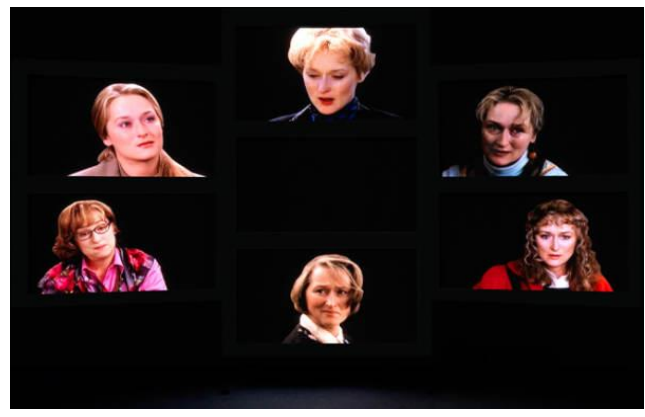

Fig. 1. Candice Breitz, "He and her 1968-2008". 


\section{ETERNITY IN MEDIA: IMMORTAL BODY}

Nam June Paik gives two explanations on the temporality of video art, one is the artistry of time, that is, the time in video art is not the real time, it is the edited time freely chosen according to the art theme; the other is the eternity of time storage, he thinks that "as long as a person is sampled into the video, he will not die." The passage of time and the disappearance of the body are irresistible to human beings. The possibility of immortality lies in being left as an image. From this point of view, media can provide a relatively eternal storage mode. In the digital age, art can be reproduced mechanically or again without time and space constraints. From the perspective of new media, new media art is a process of re media art production. The combination of body and time in new media art often has deep philosophical thinking.

In new media art, there are also grotesque bodies or injured bodies, which are often characterized by time and life events. The grotesque body makes people feel embarrassed, unhappy and even offensive, but it affirms the materiality of the body and the irresistibility of death. Julia Christian, a French philosopher and psychoanalyst, first put forward the concept of the sense of physical despicability. When people face up to the physical nature of the body and the fragility of life, they are irresistible, that is, "the impure nature of the body (fragmentary, dirty, fragile, etc.) makes people panic, which means danger, instability and uncertainty of life. Even a small wound will force people to return to the original relationship of their original understanding of the body. The imperfection of the body will make people humble and humiliated." This sense of vileness provides a violent aesthetic, either soft, or rough, or disturbing, or thought-provoking. In any case, it is the artist's praise for experiencing life with his inner time view. Hu Weiyi, the new media artist's image installation work "I quietly wait for the light to pass through the body" reflects the tiny narration of the body and the violent aesthetic characteristics of tenderness. The artist plays an other's viewing position, and puts forward a hypothesis, when all the beautiful elements are combined together, how to express the hurt, and present the pain point in a delicate and soft way. Hu creates a soft sensory experience, and the sadness he reveals creates the pain when he looks at the beauty. ("Fig. 2")

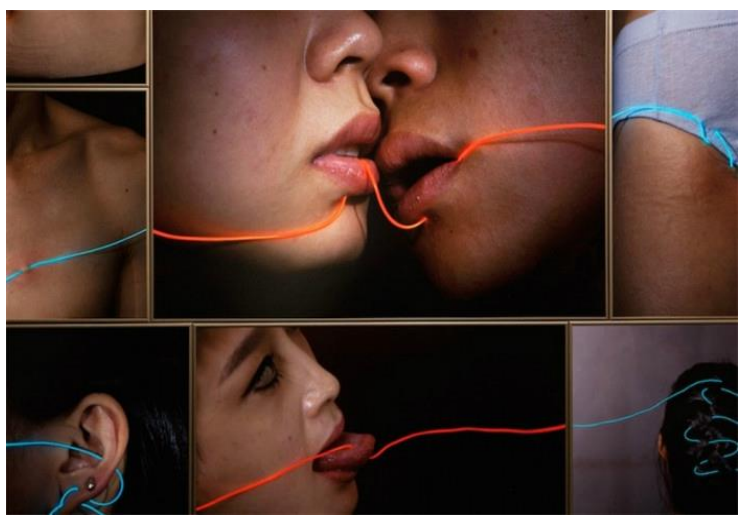

Fig. 2. Hu "quietly wait for the light to pass through the body", 2014.

The ultimate expression of life's fragility and unbearable is to face death. Some artists think about how the body is eternal by playing corpse. When photography is the mainstream medium, it is a sign of time passing. Photography sets time. When Roland Barthes talks about the image of the portrait, "the person in the portrait is not only the subject and not the object, but also a ghost constantly changing between the object and the subject." In a sense, a photographic portrait is a death mask, a coffin, a lifeless screen that suppresses breathing and feeling. Artists often look at their portraits as objects of creation. Hannah Wilke created a group of life size image works named "Intra Venus" series (1991-1992) when she was dying of lymphoid cancer. Similarly, Bob Flannagan, an artist with cystic fibrosis, created "three steps of death warning", including "video coffin", "dust to dust" and "the viewing".

\section{CONCLUSION}

Portrait can't prove the immortality of body and subject, but its transcendence exaggerates the urgency of delaying or preventing death. All attempts to find immortality in the art media have realized the continuous presence of the body subject to the greatest extent through the retention of the body image. Media (Photography) is endowed with the function of recording "reality" (the past truth), becoming the link to reappear the connection between life and death, while self-portrait becomes history or memory which is stored forever. The similarity between new media art and traditional art lies in the continuation of the media's pursuit and love for the body theme, and still plays the function of body redemption narrative. But different from it, new media art is a kind of "time-based art". Time strengthens the philosophical inquiry and artistic expression of the body. In the long river of time, people's physical body has never stopped because of the change of media. 


\section{References}

[1] Huang Minfen, Cyberfeminism: social ecology in Digital Context [J]. Journal of Jishou University(Social Sciences) [J]. 2008(05)

[2] Shao Yiyang, Body strategy and social politics: the genealogy of western contemporary body art, Art Research [J]. 2012(01)

[3] Steve Dietz,New-Media Art: Just Like Anything Else, Only Different [M]. Princeton University Press,2005.PP.85-101.

[4] Beryl Graham,"Modes of Collection,"in New Collecting: Exhibiting and Audiences after New Media [M]. Art,UK: Ashgate.2014.P.29.

[5] Rosalind Krauss, A Voyage on the North Sea: Art in the Age of the Post-Medium Condition [M]. New York: Thames \& Hudson, 2000.P.24.

[6] Halberstam, J.and I, Livingstone. (eds) .Post human Bodies [M]. Blooming ton and Indianapolis:Indiana University Press, 1995.

[7] Stephen, Wilson.Information Arts:Intersections of Art.Science, and Technology [M]. Cambrige: Mass MIT Press,2002.

[8] Hayles, N.K.How we Became Posthuman:Virtua Bodies in Cybernetics, literature, and Informatics [M]. Chicago:University of Chicago Press, 1999. 